\title{
Nonlinear control of WECS based on PMSG for optimal power extraction
}

\author{
Mohamed Makhad ${ }^{1}$, Malika Zazi $^{2}$, Azeddine Loulijat ${ }^{3}$ \\ ${ }^{1,2}$ Department of Electrical Engineering, Mohamed V University, Morocco \\ ${ }^{3}$ Faculty of Sciences and Technology, Hassan First University, Morocco
}

\begin{tabular}{l} 
Article Info \\
Article history: \\
Received May 28, 2019 \\
Revised Nov 16, 2019 \\
Accepted Dec 6, 2019 \\
\hline Keywords: \\
Integral backstepping control \\
MPPT \\
PMSG \\
WECS
\end{tabular}

\begin{abstract}
This paper proposes a robust control strategy for optimizing the maximum power captured in Wind Energy Conversion Systems (WECS) based on permanent magnet synchronous generators (PMSG), which is integrated into the grid. In order to achieve the maximum power point (MPPT) the machine side converter regulates the rotational speed of the PMSG to track the optimal speed. To evaluate the performance and effectiveness of the proposed controller, a comparative study between the IBC control and the vector control based on PI controller was carried out through computer simulation. This analysis consists of two case studies including stochastic variation in wind speed and step change in wind speed.
\end{abstract}

Copyright (C) 2020 Institute of Advanced Engineering and Science. All rights reserved.

\section{Corresponding Author:}

Mohamed Makhad,

Department of Electrical Engineering,

Mohammed V University,

Royal Army Avenue, B.P. 6207 Rabat-Morocco.

Email: mohamed.makhad@um5s.net.ma

\section{INTRODUCTION}

Recently, sustainable energy sources recognized as competitive sources of electrical energy. Despite all these benefits, wind energy is highly intermittent and unpredictable. Therefore, the production of electrical power should not be based exclusively on the wind energy sources, as they are not reliable [1, 2]. Due to these significant advantages in the generation of electrical power, Variable Speed Wind Turbine (VSWT) have been the most extensively installed [3]. Among the generators installed in wind generation systems, the Doubly Fed Induction Generator (DFIG) has an attractive features [3]. The main advantages of the DFIG are: High fault tolerance, low switching loss in rotor-side converters, small size and low cost of converters as compared to the one used in the PMSG [4].

To extract the maximum power, the wind turbine power coefficient should be maintained at its maximum value despite wind variations. This method is carried out using an algorithm called MPPT which delivers the optimal rotational speed $[5,6]$. Therefore, to place the system at the point of maximum power, the machine side converter (MSC) control strategy should be effective and robust under real operating conditions. In the literature, Vector control (VC) based on conventional PI correctors is the most popular strategy implemented in many industrial applications [7]. The performances of the PI controller are poor, because the PMSG-based WECS is a variable structure system, while the PI controller is a linear controller which is adjusted for a specific system operating point, so accurate information about system parameters and charging conditions is necessary to ensure good performances [8].

To overcome these drawbacks, many nonlinear control strategies have been successfully designed to extract the maximum energy from the WECS based on PMSG and optimize integration into the electrical distribution grid, such as Fuzzy Logic Control [9], Feedback Linearization technique [10], SMC [8]. 
In [11], to reduce hardware complexity, the authors have developed a Modified Particle Swarm Optimization (MPSO) Backpropagation Learning Algorithm to adjust PI parameters with sensorless control of a PMSG to achieve high performances in MPPT operation. The MPSO is also used by is [12] to optimise the MPPT algorithm in a Wind-Tidal Hybrid. In [13], the authors designed a robust nonlinear predictive control (RNPC) to regulate the reference voltages and stator currents of the PWM rectifier in presence of matched uncertainties and external disturbances, with validation via implementation on a dSPACE hardware. In [14], the authors developed a higher order SMC controller with hardware implementation. for a variable speed wind turbine based on PMSG integrated to an infinite power grid. Moreover, the Backstepping approach it is one of the most a nonlinear controllers suggested for the VSWT [15].

The main objective of the MSC control is to place the operating point of the WECS at the maximum power point (MPP). To achieve this goal, the control regulates the rotational speed of PMSG to track the optimal speed. For the GSC converter control, the purposes are: regulatation of the DC bus voltage and to ensure a connection to the electrical network with a unit power factor (UPF). This paper is organized as follows: Section 2 presents the mathematical model of the system composed of the wind turbine and the PMSG. In the third section the proposed IBC control strategy for maximizing the extracted power is designed. The simulation results are presented and compared in section four. Finally, in the last section a brief conclusion is included. Figure 1 illustrates the configuration of a PMSG-based wind energy conversion system connected to the power grid.

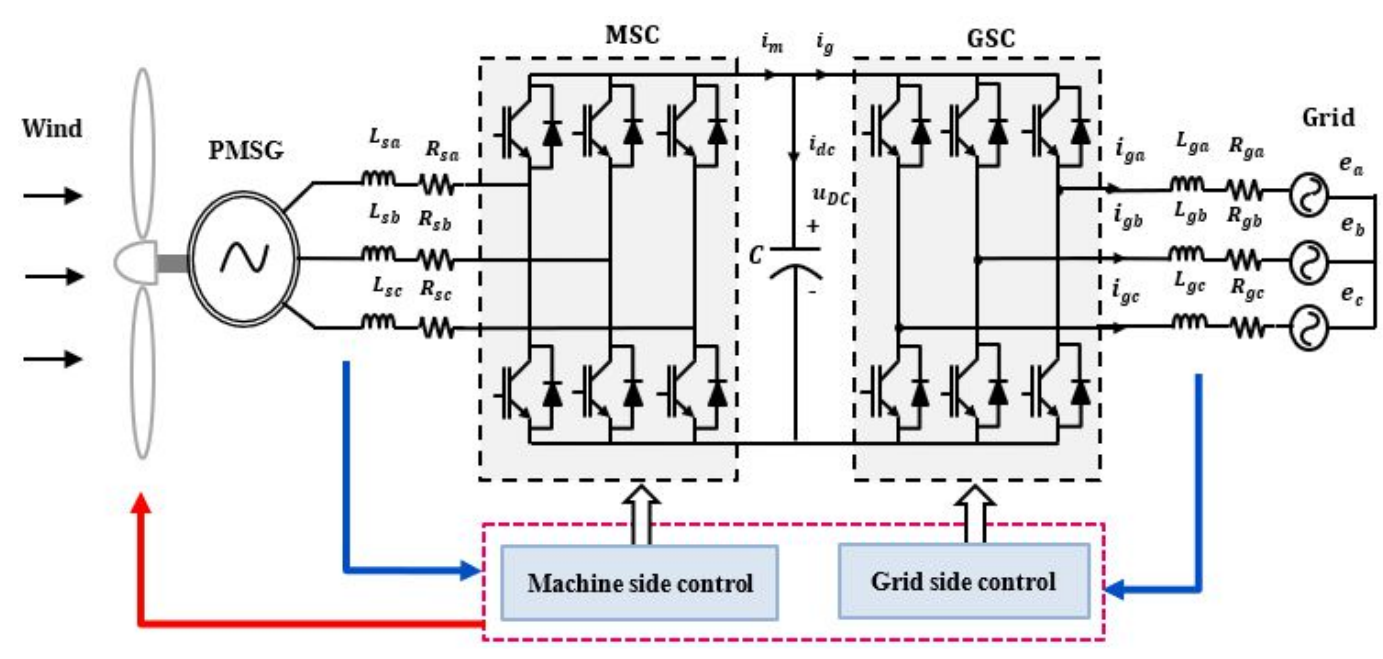

Figure 1. Configuration of WECS based on PMSG

\section{MATHEMATICAL MODEL OF WIND TURBINE}

In this section the mathematical simplified turbine model is proposed. The expression of the mechanical power $P_{T}$ extracted from the wind and the tip-speed ratio $\lambda$ are given by:

$$
\left\{\begin{array}{l}
P_{T}=\frac{1}{2} \cdot C_{p}(\lambda, \beta) \cdot \rho \cdot \pi \cdot R^{2} \cdot V^{3} \\
\lambda=\frac{R \cdot \omega_{m}}{V}
\end{array}\right.
$$

where: $\mathrm{V}$ the wind speed $(\mathrm{m} / \mathrm{s}) . \rho$ is the air density. $R$ is the rotor blade radius. $C_{p}(\lambda, \beta)$ is the power coefficient and $\omega_{m}$ is the rotational speed $(\mathrm{rad} / \mathrm{s})$. Based on the turbine characteristics, a generic equation employed to describe the power coefficient $C_{p}(\lambda, \beta)$ can be expressed as follows [16]:

$$
C_{p}(\lambda, \beta)=0,22 .\left(\frac{116}{\lambda_{i}}-0,4 . \beta-5\right) e^{\frac{-12.5}{\lambda_{i}}} ; \frac{1}{\lambda_{i}}=\frac{1}{\lambda+0.089 \beta}-\frac{0.035}{\beta^{3}+1}
$$

Int J Elec \& Comp Eng, Vol. 10, No. 3, June 2020 : 2815 - 2823 
The variation of the coefficient $C_{p}(\lambda, \beta)$ as a function of tip speed ratio for various values of the pitch angle $\beta$ is given in the Figure 2(a). while Figure 2(b) presents the curves of the mechanical power $P_{T}$ in function of rotational speed $\omega_{m}$ for various wind speed. As illustrated in Figure 2(b), the WECS operation consists of four zones. Zone 1 and 4 corresponding to the shut-down of the wind turbine when the wind speed is below and exceeds the limits of the speed operating range, respectively. In zone 2 the wind turbine operates in MPPT mode, in order to extract the maximum power available. Zone 3 corresponds to constant power mode operation through the activation of the pitch angle controller. The characteristics in Figure 2(b) show that the maximum power coefficient $C_{p}=0.43$ is obtained for $\lambda_{\text {opt }}=6.42$ and pitch angle $\beta=0$.
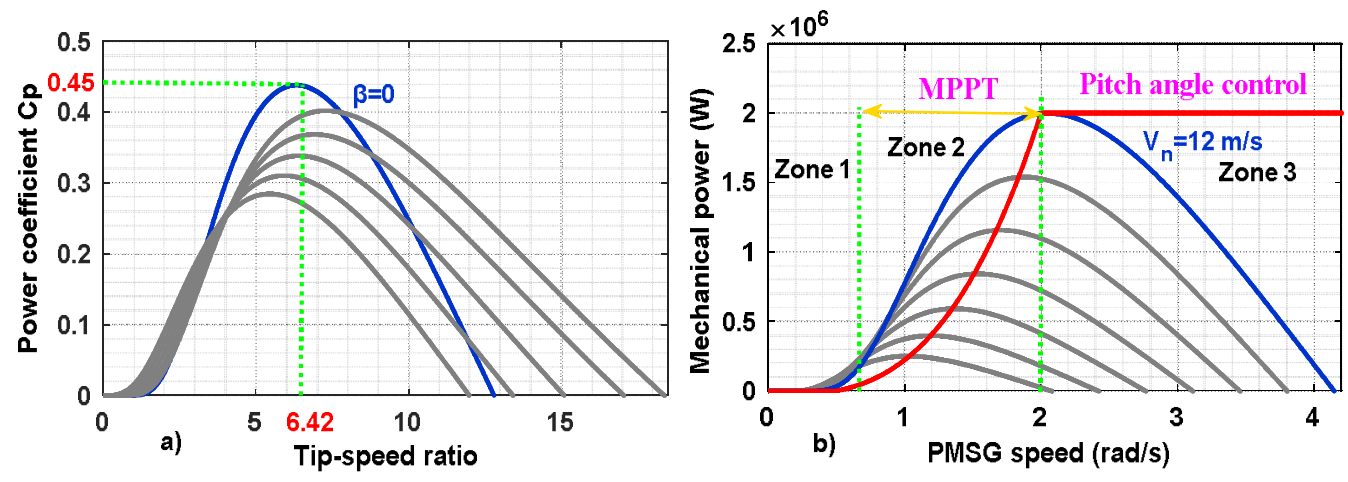

Figure 2. (a) Characteristics $C_{p}(\lambda, \beta)$ for various values of the pitch angle $\beta$, (b) Mechanical power curves at various wind speed

\section{DYNAMIC MODEL OF PMSG}

The mathematical model of the PMSG in in the synchronous frame $(d-q)$ is described by the following equations $[17,18]$ :

$$
\begin{aligned}
& \left\{\begin{array}{l}
\dot{i}_{s d}=-\frac{R_{s}}{L_{s d}} i_{s d}+\omega_{s} \frac{L_{s q}}{L_{s d}} i_{s q}+\frac{v_{s d}}{L_{s d}} \\
\dot{i}_{s q}=-\frac{R_{s}}{L_{s q}} i_{s q}-\omega_{s} \frac{L_{s d}}{L_{s q}} i_{s d}-\omega_{s} \frac{\psi_{f}}{L_{s q}}+\frac{v_{s q}}{L_{s q}}
\end{array}\right. \\
& \left\{\begin{array}{l}
T_{e}=\frac{3}{2} p \psi_{f} i_{s q} \\
\dot{\omega}_{m}=\frac{T_{e}}{J}-\frac{f}{J} \omega_{m}-\frac{T_{r}}{J}
\end{array}\right.
\end{aligned}
$$

where: $v_{s d}, v_{s q}$ are stator voltage components in d-q reference frame. $i_{s d}, i_{s q}$ are stator current components in d-q reference frame. $\psi_{f}$ is permanent flux linkage. $R_{s}$ is the stator resistance. $\omega_{s}$ is the electrical speed $(\mathrm{rad} / \mathrm{s}) . p$ is number of pole pairs. $L_{s d}$ and $L_{s q}$ are stator inductance components in d-q reference frame. $T_{e}$ is the electromagnetic torque of the PMSG. $J$ is the total moment of inertia. $f$ is the viscous friction coefficient. $T_{r}$ is the mechanical torque developed by the wind turbine. $\omega_{m}$ is the rotational speed of the PMSG.

\section{INTEGRAL BACKSTEPPING CONTROL DESIGN}

In this section the The Integral backsteping controllers is designed for control the MSC in WECS based on PMSG. The IBC control based on the decomposition of the system into subsystems in descending order, while checking the stability of each subsystem in the sense of Lyapunov, which gives it the qualities of robustness and overall asymptotic stability [19-21]. The Backstepping approach involves the recursive selection of certain functions of state variables as virtual control inputs for dimensional subsystems [22-25].

Nonlinear control of WECS based on PMSG for optimal power extraction (Mohamed Makhad) 


\subsection{Design of rotational speed controller}

For dynamics (4), the speed error $e_{m}$ is defined as follows:

$$
e_{m}(\mathrm{t})=\omega_{m}{ }^{*}-\omega_{m}+\kappa_{1} \cdot \int\left(\omega_{m}^{*}-\omega_{m}\right) \mathrm{dt}
$$

where: $\kappa_{1}$ is constant of integral action.

Theorem 1: the following virtual control ensures the asymptotic convergence of the dynamics (4):

$$
i_{s q}^{*}=\frac{2 J}{3 p \psi_{f}}\left(\kappa_{m} e_{m}+\dot{\omega}_{m}^{*}+\frac{f}{J} \omega_{m}+\frac{T_{r}}{J}+\kappa_{1} \cdot\left(\omega_{m}{ }^{*}-\omega_{m}\right)\right)
$$

where: $\kappa_{m}$ is a positive control gain that depends on the MSC features.

Proof : to prove that $\omega_{m}$ tracks the optimal speed $\omega_{m}^{*}$, consider the Lyaponov function $V_{1}$ definite by:

$$
V_{1}=0.5 e_{\omega}^{2}
$$

the derivative of $V_{1}$ along the trajectory is given by:

$$
\dot{V}_{1}=e_{m} \dot{e}_{m}=e_{m}\left(\dot{\omega}_{m}{ }^{*}-\frac{3}{2} \frac{p}{J} \psi_{f} i_{s q}^{*}+\frac{f}{J} \omega_{m}+\frac{T_{r}}{J}+\kappa_{1} \cdot\left(\omega_{m}{ }^{*}-\omega_{m}\right)\right)
$$

substituting (6) in (8), we prove that :

$$
\dot{V}_{1}=-\kappa_{m} e_{m}^{2} \leq 0
$$

based on the inequality (9), the asymptatic stability of the subsystem (4) is guaranteed if the gain $\kappa_{m}$ is positive. This completes the proof.

\subsection{Currents controller design}

To ensure that $i_{s q}$ tracks the current $i_{s q}^{*}$, the current error is defined as follows:

$$
e_{q}(t)=i_{s q}{ }^{*}-i_{s q}+\beta_{1} \int\left(i_{s q}{ }^{*}-i_{s q}\right) d t=i_{s q}{ }^{*}-i_{s q}+e_{q}^{\prime}
$$

where: $\beta_{1}$ is constant of integral action.

Theorem 2: the following voltage control $v_{s q}^{*}$ ensure that $i_{s q}$ tracks the current $i_{s q}^{*}$ :

$$
v_{s q}^{*}=L_{s q}\left(\beta_{q} e_{q}+\dot{i}_{s q}^{*}+\frac{R_{s}}{L_{s q}} i_{s q}+\omega_{s} \frac{L_{s d}}{L_{s q}} i_{s d}+\omega_{s} \frac{\psi_{f}}{L_{s q}}\right)
$$

where: $\beta_{q}$ is a positive control gain, chosen according to the requirements imposed by the MSC.

Proof: to to confirm that the trajectory of the subsystem (3.a) converge to the current reference. Consider a second Lyapunov function chosen as follows:

$$
V_{2}=V_{1}+0.5 \mathrm{e}_{q}^{2}+0.5 . e_{q}^{2}
$$

the time derivative of $V_{2}$ is given by:

$$
\dot{V}_{2}=-\kappa_{m} \cdot e_{m}{ }^{2}+e_{q} \dot{e}_{q}+e_{q}^{\prime} \dot{e}_{q}^{\prime}=-\kappa_{m} \cdot e_{m}{ }^{2}+e_{q}\left(\dot{i}_{s q}{ }^{*}-\dot{i}_{s q}+\dot{e}_{q}^{\prime}\right)+\dot{e}_{q}^{\prime} \dot{e}_{q}^{\prime}
$$

after simplification the expression (13) becomes:

$$
\dot{V}_{2}=-\kappa_{m} \cdot e_{m}^{2}-\left(\beta_{q}-\beta_{1}\right) e_{q}^{2}-\beta_{1} e_{q}^{2} \text { if } \beta_{q} \geq \beta_{1} \text { then }: \dot{V}_{2} \leq 0
$$

in order for the closed loop (3.a) to be asymptotically stable, the condition $\beta_{q} \geq \beta_{1}$ must be verified. This completes the proof.

Int J Elec \& Comp Eng, Vol. 10, No. 3, June 2020 : 2815 - 2823 
In this second step to regulate the d-axis current, the d-axis error $e_{d}$ is defined by:

$$
e_{d}(t)=i_{s d}^{*}-i_{s d}+\alpha_{1} \int\left(i_{s d}^{*}-i_{s d}\right) d t=i_{s d}^{*}-i_{s d}+e_{d}^{\prime}
$$

where: $\alpha_{1}$ is a positive control gain, the value is dependent on the MSC features.

Theorem 3: the following voltage control $v_{s d}^{*}$ assures the asymptotical convergence to zero of the d-axis error:

$$
v_{s d}^{*}=L_{s d}\left(\alpha_{d} e_{d}+\frac{R_{s}}{L_{s d}} i_{s d}-\omega_{s} \frac{L_{s q}}{L_{s d}} i_{s q}\right)
$$

where: $\alpha_{d}$ is a positive parameter chosen according to the requirements imposed by the MSC.

Proof: to check the stability of subsystem (3.b), a third candidate function Lyapunov $V_{3}$ is defined as follows:

$$
V_{3}=0.5 \mathrm{e}_{d}^{2}+0.5 \cdot e_{d}^{2}
$$

deriving $V_{3}$ with respect to time we obtain:

$$
\dot{V}_{3}=-\alpha_{d} e_{d}^{2}+\alpha_{1}\left(e_{d}^{2}-e_{d}^{2}\right)=-\left(\alpha_{d}-\alpha_{1}\right) e_{d}^{2}-\alpha_{1} e_{d}^{2}
$$

finally, if $\alpha_{d} \geq \alpha_{1}$ then $\dot{V}_{3} \leq 0$, as a result the dynamic (3.b) is asymptically stable. This completes the proof.

\section{SIMULATION RESULTS AND DISCUSSIONS}

This section presents the simulation results of the WECS based on a 2MW PMSG. The PMSGbased WECS presented in Figure 1 was simulated in Matlab/Simulink environment. In addition, the PMSG parameters and the controller gains are given in Tables 1 and 2, respectively. The performance and feasibility of the IBC control are compared to that of PI corrector under four cases, stochastic wind speed variation and step change of wind speed. The IBC control strategy scheme is presented in Figure 3.

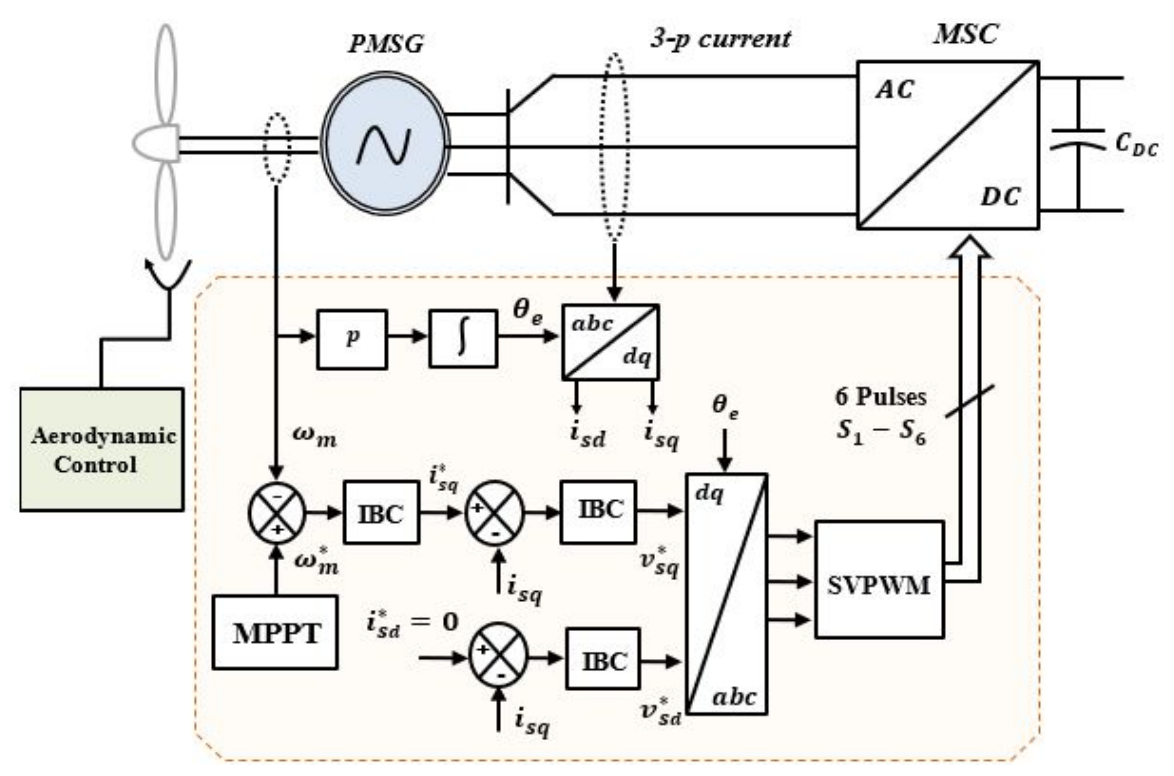

Figure 3. Block diagram of the IBC controller 
Table 1. Parameters of the WECS based on PMSG [18]

\begin{tabular}{llll}
\hline PMSG parameters & Values & Wind turbine parameters & Values \\
\hline $\boldsymbol{P}_{\boldsymbol{r}}$ rated power & $2 \mathrm{MW}$ & $\rho$ the air density & $1.08 \mathrm{~kg} / \mathrm{m}^{3}$ \\
$\boldsymbol{\omega}_{\boldsymbol{m}}$ mechanical speed & $2.57 \mathrm{rad} / \mathrm{s}$ & $V$ base wind speed & $12 \mathrm{~m} / \mathrm{s}$ \\
$\boldsymbol{R}$ stator resistor & $0.008 \Omega$ & $\mathrm{C}_{\text {pmax }}$ optimal power coefficient & $37 \mathrm{~m}$ \\
d-axis and q-axis inductance & $0.0003 \mathrm{H}$ & $R$ blade radius & 0.43 \\
$\boldsymbol{\Psi}_{\boldsymbol{f}}$ Permanent flux & $3.86 \mathrm{~Wb}$ & $\lambda_{\text {opt }}$ Optimal tip speed ratio & 673 \\
$\mathrm{P}$ pole pairs & 60 & & \\
\hline
\end{tabular}

Table 2. IBC control gains

\begin{tabular}{llllll}
\hline$\kappa_{m}$ & 0.001 & $\beta_{d}$ & 5000 & $\alpha_{q}$ & 5000 \\
\hline$\kappa_{1}$ & 60 & $\beta_{1}$ & 70 & $\alpha_{1}$ & 70 \\
\hline
\end{tabular}

\subsection{Operation under stochastic wind speed variation}

In this case a stochastic wind speed profile is simulated to investigate the performance of the proposed controllers in response to a more realistic wind speed. the wind speed varies between $8 \mathrm{~m} / \mathrm{s}$ and $12 \mathrm{~m} / \mathrm{s}$, exceeding the rated speed from the instant $\mathrm{t}=5.8 \mathrm{~s}$ to $\mathrm{t}=7 \mathrm{~s}$. The simulation results are presented in Figure 4 and Figure 5. For greater visibility, the simulation results are presented irrespective of the ripples generated by Pulse Width Modulation (PWM). As shown in Figure 4(a), the pitch angle is set to zero in MPPT operation. From $t=5.8 \mathrm{~s}$ to $7 \mathrm{~s}$, the wind speed exceeds $v=12 \mathrm{~m} / \mathrm{s}$. In this particular situation, the pitch angle controller is enabled, hence the angle $\beta$ is adjusted in the range $0^{\circ}$ to $4^{\circ}$ in order to limit the output power of the PMSG. According to Figure 4(b) at variable speed the IBC controller is able to track the optimal speed with higher precision as compared to PI controller.
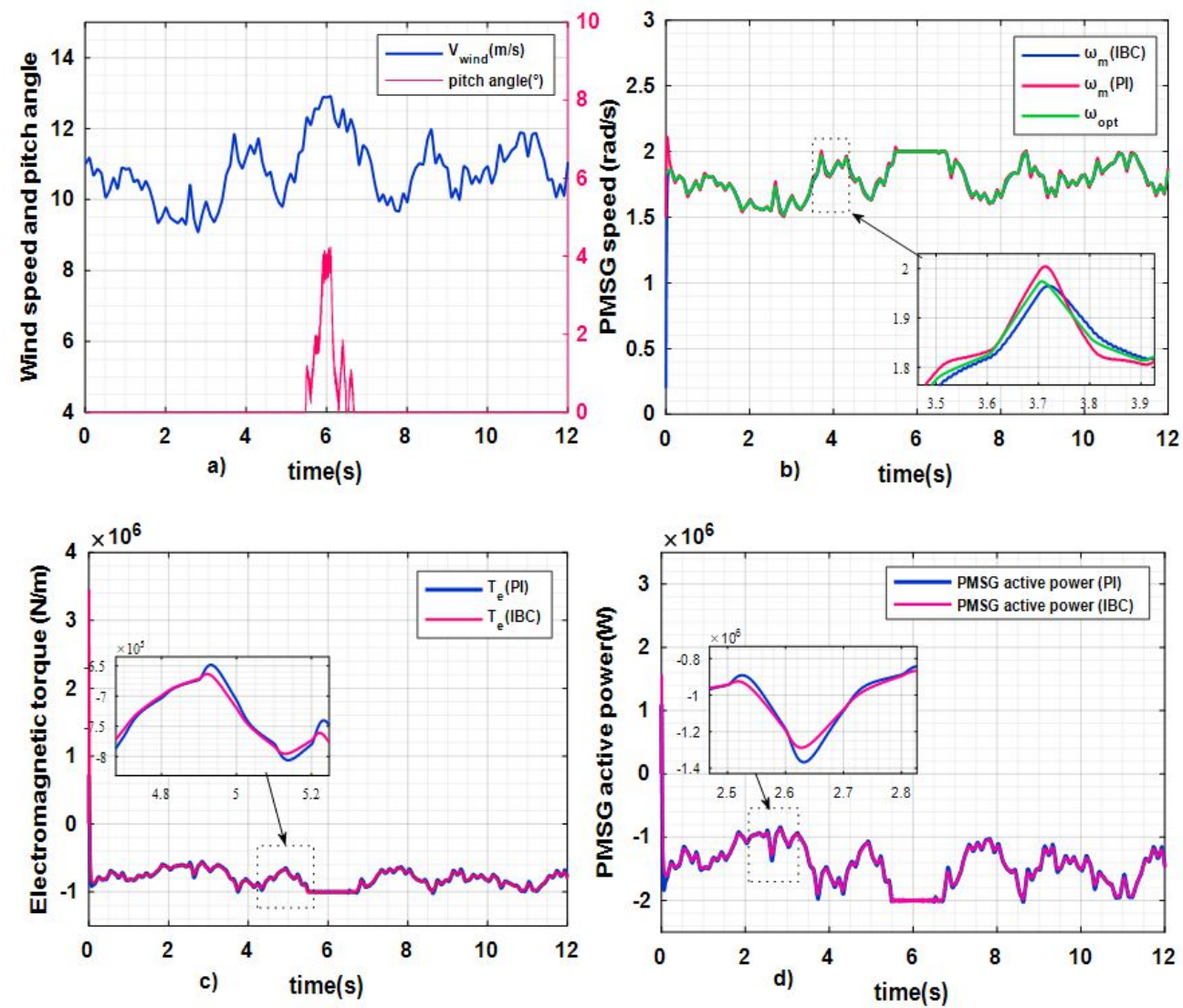

Figure 4. (a) Wind speed profile and pitch angle, (b) PMSG speed, (c) Generator torque, (d) PMSG active power

Int J Elec \& Comp Eng, Vol. 10, No. 3, June 2020 : 2815 - 2823 
Figure 4(c) and Figure 4(d) indicate that the IBC control provides good performance at variable speed in terms of extracting the maximum power compared to that obtained with the PI controller. While, in the range $\mathrm{t}=5.8 \mathrm{~s}$ to $7 \mathrm{~s}$, it can be seen that the torque and power are limited to the rated values by the pitch angle control. As mentioned in Table 3, it is obvious that the current and DC bus voltage ripples are very high under the IBC control compared to the PI corrector. Finally, Figure 5(b) presents the measurement of the total harmonic distortion (THD) of stator currents at moments $t=2 \mathrm{~s}, \mathrm{t}=5 \mathrm{~s}$ and $\mathrm{t}=10 \mathrm{~s}$. From these data, we can remark that the THD under IBC controller is slightly higher than those obtained with PI control. Noting that the high frequency ripples produced by the IBC controller due to the nonlinear aspect of this approach.

Table 3. Performance achieved by the two controllers

\begin{tabular}{ccc}
\hline & PI controller & IBC \\
\hline UDC ripple & $\pm 2.8 \mathrm{~V}$ & $3 \mathrm{~V}$ \\
Id ripple & $\pm 0.02 \mathrm{pu}$ & $\pm 0.015 \mathrm{pu}$ \\
Iq ripple & $\pm 0,004 \mathrm{pu}$ & $\pm 0.0095 \%$ \\
Max tracking error & $\pm 4 \%$ & $\pm 0,45 \%$ \\
\hline
\end{tabular}
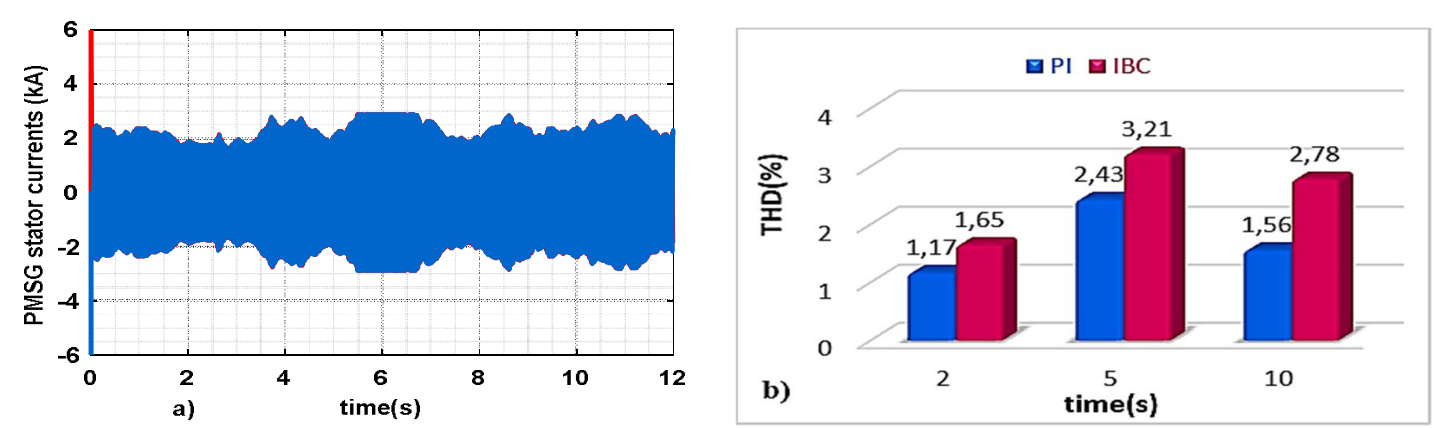

Figure 5. (a) PMSG stator currents Iabc, (b) Total harmonic distorsion (THD) of stator currents

\subsection{Operation under step change of wind speed}

To evaluate the transient and steady state performances obtained by the controllers studied during an abrupt change in wind speed, a series of two consecutive step changes in wind speed are applied as follows: $8 \mathrm{~m} / \mathrm{s}$ to $10 \mathrm{~m} / \mathrm{s}, 10$ to $12 \mathrm{~m} / \mathrm{s}$, at $\mathrm{t}=2 \mathrm{~s}$ and $\mathrm{t}=10 \mathrm{~s}$, respectively. The simulation responses are provided in Figure 6 and Figure 7. Figure 6(b) presents the PMSG rotational velocity in response to two consecutive steps of wind speed under the PI and IBC controllers. This figure shows that both regulators have good steady-state performance.
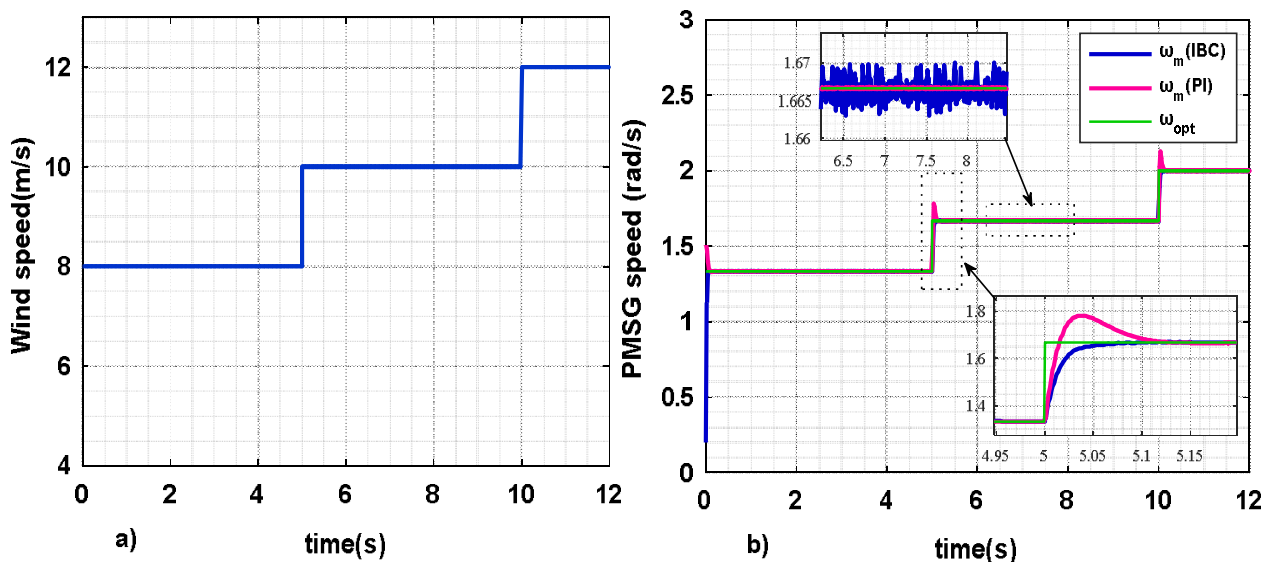

Figure 6. (a) Wind speed profile, (b) PMSG speed ( $\mathrm{rad} / \mathrm{s})$ 
During transient operation, under the two controllers, the speed response time is $0.15 \mathrm{~s}$, with a considerable overshoot under the PI corrector. it is important not to forget that the steady-state speed ripples are very high under the IBC control owing to the nonlinear design of the Backstepping control. As illustrated in Figure 7(a), the waveform of the power coefficient under the IBC and PI controllers are identical transient response with a small derivation. In Figure 7(c) and Figure 7(d), the IBC controller provides smoother operation compared to PI controller.
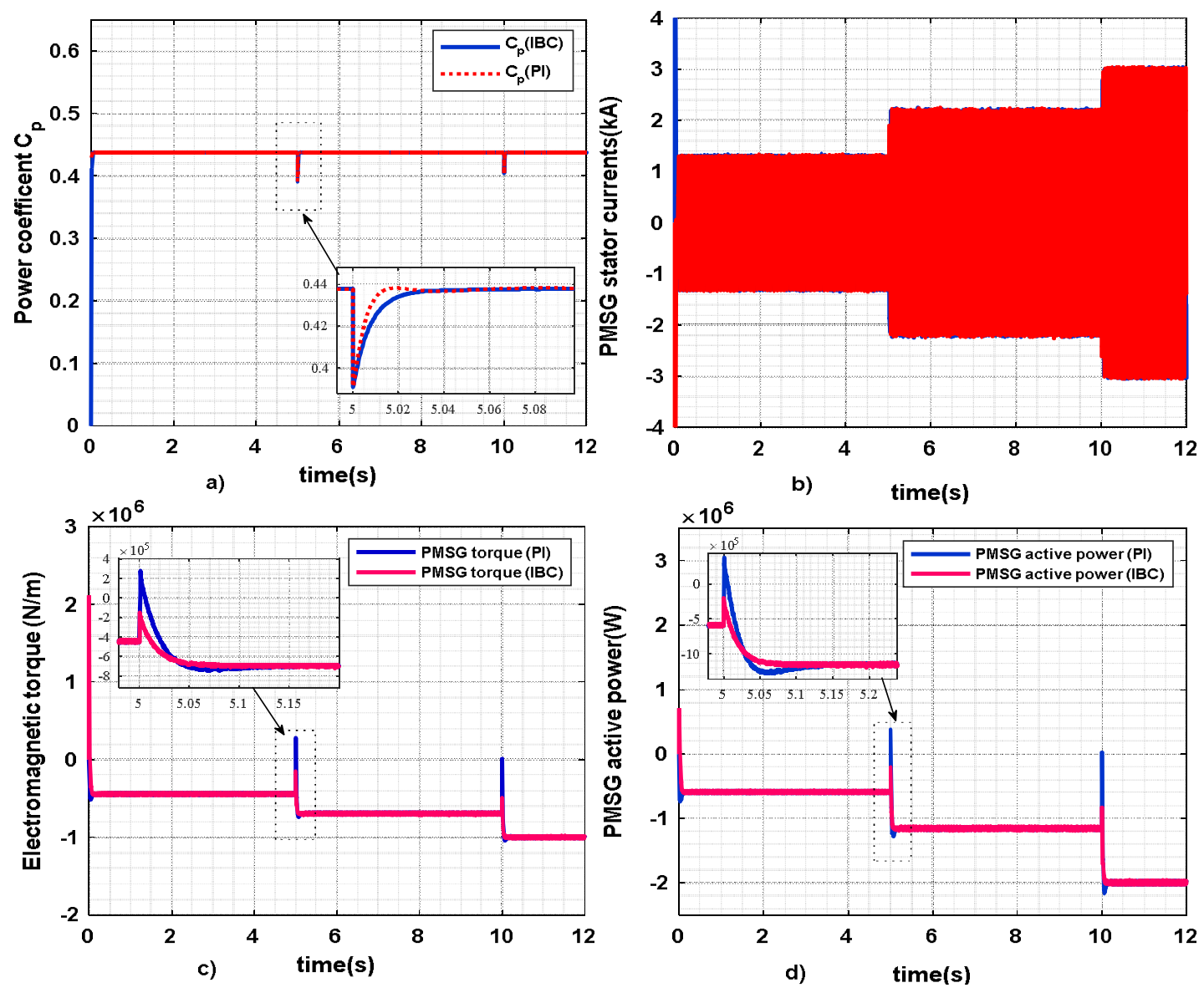

Figure 7. (a) Power coeffient, (b) Stator currents of the PMSG, (c) PMSG torque, (d) PMSG active power

\section{CONCLUSION}

A novel Integral Backstepping controller is designed in the paper in order to achieve MPPT of a PMSG based variable speed wind turbine. An evaluation of the performance and effectiveness of the propsed controller is compared with that obtained by the conventional PI corretor through two case studies: step change in wind speed and stochastic change in wind speed. The simulation results show that classical PI-controller has poor performance during transient operation, especially in MPPT operation. The two case studies confirmed that that IBC can rapidly reach the MPPT with the least overshoot under step change in wind speed and stochastic change in wind speed. However, the THD of stator currents indicates that the deformation of the stator currents under the IBC is slightly higher in comparison with the one of PI controller. This THD value is a result of the nonlinear design of the IBC control. Thanks to this comparative analysis, we can say that the robust Integral Backstepping controller is an attractive technique in the control of wind energy conversion systems (WECS) based on PMSG. 


\section{REFERENCES}

[1] Y. Nakanishi, T. Saito, and R. Yokoyama, "Wind power generation," Energy Technology Roadmaps of Japan, Springer, Tokyo, pp. 307-322, 2016.

[2] S. Heier, "Grid Integration of Wind Energy: Onshore and Offshore Conversion Systems," 3rd Edition, 2014.

[3] P. W. Carlin, A. S. Laxson, and E. B. Muljadi, "The history and state of the art of variable-speed wind turbine technology," Wind Energy, vol. 6, no. 2, pp. 129-159, 2003.

[4] Y. Amirat, M. Benbouzid, and B. Bensaker, "The State of the Art of Generators for Wind Energy Conversion Systems," Proceedings of the International Conference on Electrical Machines (ICEM), vol. 14, Chania, Greece, pp. 243-248, 2010.

[5] H.-W. Kim, S.-S. Kim, and H.-S. Ko, "Modeling and control of PMSG-based variable-speed wind turbine," Electr. Power Syst. Res., vol. 80, no. 1, pp. 46-52, 2010.

[6] M. Bouderbala, B. Bossoufi, A. Lagrioui, M. Taoussi, H. A. Aroussi, and Y. Ihedrane, "Direct and indirect vector control of a doubly fed induction generator based in a wind energy conversion system," International Journal of Electrical and Computer Engineering (IJECE), vol. 9, no. 3, pp. 1531-1540, 2019.

[7] A. Murray, M. Palma, and A. Husain, "Performance comparison of permanent magnet synchronous motors and controlled induction motors in washing machine applications using sensorless field oriented control," in Conference Record-IAS Annual Meeting (IEEE Industry Applications Society), pp. 1-6, 2008.

[8] B. Beltran, T. Ahmed-Ali, and M. E. H. Benbouzid, "High-order sliding-mode control of variable-speed wind turbines," IEEE Trans. Ind. Electron., vol. 56, no. 9, pp. 3314-3321, 2009.

[9] A. Z. Mohamed, M. N. Eskander, and F. A. Ghali, "Fuzzy logic control based maximum power tracking of a wind energy system," Renew. Energy, vol. 23, no. 2, pp. 235-245, 2001.

[10] W. Qiao, L. Qu, and R. G. Harley, "Control of IPM synchronous generator for maximum wind power generation considering magnetic saturation," IEEE Trans. Ind. Appl., vol. 45, no. 3, pp. 1395-1105, 2009.

[11] C. M. Hong, C. H. Chen, and C. S. Tu, "Maximum power point tracking-based control algorithm for PMSG wind generation system without mechanical sensors," Energy Convers. Manag., vol. 69, pp. 58-67, 2013.

[12] F. D. Wijaya, K. D. Pribadi, and Sarjiya, "Maximum power point tracking using particle swarm optimization algorithm for hybrid wind-tidal harvesting system on the south coast of Java," Int. J. Electr. Comput. Eng., vol. 7, no. 2, pp. 659-666, 2017.

[13] R. Aissou, T. Rekioua, D. Rekioua, and A. Tounzi, "Corrigendum to 'Robust nonlinear predictive control of permanent magnet synchronous generator turbine using Dspace hardware," International Journal of Hydrogen Energy, vol. 42, no. 5, pp. 21047-01056, 2017.

[14] A. Merabet, K. T. Ahmed, H. Ibrahim, and R. Beguenane, "Implementation of Sliding Mode Control System for Generator and Grid Sides Control of Wind Energy Conversion System," IEEE Trans. Sustain. Energy, vol. 7, no. 3, pp. 1327-1335, 2016.

[15] Y. Errami, A. Obbadi, S. Sahnoun, M. Ouassaid, and M. Maaroufi, "Proposal of a backstepping control strategy for dynamic performance improvement of PMSG Wind Farm with common DC bus," Proc. 2016 Int. Renew. Sustain. Energy Conf. IRSEC, pp. 397-404, 2017.

[16] M. Chinchilla, S. Arnaltes, and J. C. Burgos, "Control of permanent-magnet generators applied to variable-speed wind-energy systems connected to the grid," IEEE Trans. Energy Convers., vol. 21, no. 1, pp. 130-135, 2006.

[17] A. H. Kasem Alaboudy, A. A. Daoud, S. S. Desouky, and A. A. Salem, "Converter controls and flicker study of PMSG-based grid connected wind turbines," Ain Shams Eng. J., vol. 4, no. 1, pp. 75-91, 2013.

[18] Y. Errami, M. Ouassaid, and M. Maaroufi, "A performance comparison of a nonlinear and a linear control for grid connected PMSG wind energy conversion system,” Int. J. Electr. Power Energy Syst., vol. 68, pp. 180-194, 2015.

[19] M. Karabacak, H.I. Eskikurt, "Design, modelling and simulation of a new nonlinear and full adaptive backstepping speed tracking controller for uncertain PMSM,” Appl. Math. Model., vol. 36, no. 11, pp. 5199-5213, 2012.

[20] H. Bahri, M. Aboulfatah, M. Guisser, E. Abdelmounim, and M. El Malah, "Integral backstepping control for maximum power point tracking and unity power factor of a three phase grid connected photovoltaic system," International Journal of Electrical and Computer Engineering (IJECE), vol. 7, no. 4, pp. 1671-1680, 2017.

[21] Q. Guo, P. Sun, J. Yin, T. Yu, and D. Jiang, "Parametric adaptive estimation and backstepping control of electro-hydraulic actuator with decayed memory filter," ISA Trans., vol. 62, pp. 202-214, 2016.

[22] N. Adhikary and C. Mahanta, "Integral backstepping sliding mode control for underactuated systems: Swing-up and stabilization of the Cart-Pendulum System," ISA Trans., vol. 52, no. 6, pp. 870-880, 2013.

[23] M. Madark, A. Ba-Razzouk, E. Abdelmounim, and M. El Malah, "A new induction motor adaptive robust vector control based on backstepping," International Journal of Electrical and Computer Engineering (IJECE), vol. 7, no. 4, pp. 1983-1993, 2017.

[24] M. El Malah, A. Ba-razzouk, M. Guisser, E. Abdelmounim, and M. Madark, "Backstepping Control for MPPT and UPF of a Three Phase Single Stage Grid Connected PV System," IAES International Journal of Robotics and Automation (IJRA), vol. 7, no. 4, pp. 262-272, 2018.

[25] F. Mazenc and P. A. Bliman, "Backstepping design for time-delay nonlinear systems," IEEE Trans. Automat. Contr., 2006. 